\title{
Comparative Study Between Appendiceal Base Ligation with Hand-Made Endoloop Knot Pusher Versus Standard Endoloop in Laparoscopic Appendectomy
}

\author{
MOHAMMED A. ELBANNA, M.Sc.; OSAMA H. ABDRABOH, M.D.; TAHA A. ISMAEL, M.D.; \\ SOLIMAN M. SOLIMAN, M.D. and MAHMOUD M. ELSHERIF, M.D.
}

The Department of Gastrointestinal, Liver and Laparoscopic Surgery, Faculty of Medicine, Tanta University

\begin{abstract}
Background: Using hand-made (endoloop and knot pusher) technique has the same reliability of the other methods in appendiceal base ligation in addition to the significant lower cost in comparison with standard endoloop.
\end{abstract}

Aim of Study: Is to compare between appendiceal base ligation with hand-made Endoloop knot pusher versus standard endoloop in laparoscopic appendectomy.

Patients and Methods: This prospective randomized comparative study was carried out in Gastrointestinal, Liver \& Laparoscopic Surgery unit of Tanta University Hospitals from May 2017 till May 2018 on 40 patients with acute appendicitis divided into two equal groups; Group I: Were subjected to ligation of the base of the appendix with standard endoloop (commercial) in laparoscopic appendectomy (20 cases). Group II: Were subjected to ligation of the base of the appendix with hand-made endoloop knot pusher in laparoscopic appendectomy (20 cases).

Results: The mean age of group I was $29 \pm 5.10$ years, compared to $29.33 \pm 5.39$ in-group II, there were 12 males and 8 females in group I, while there were 10 males and 10 females in group II. Statistically significant difference was present in operative time between both groups; group I had operative time mean of $46.07 \pm 11.70$ minutes compared to $54.73 \pm 11.33$ minutes in-group II. A highly statistically significant difference in appendiceal base ligation cost between both groups; group I with Mean $69.10 \pm 10.41$ USD compared to $7.75 \pm 1.77$ USD in group II. Superficial wound infection developed in one patient in group I and two patients in group II, also each group had only one patient with postoperative ileus, only one patient in group II developed postoperative abscess in the RIF.

Conclusion: Using hand-made endoloop knot pusher technique and standard endoloop were proved safe, as both were not associated with major morbidity. Complications rate, hospital stay were average with other studies, Using hand-made endoloop knot pusher technique has significant lower cost in comparison with standard endoloop as it is reusable. However, hand-made endoloop knot pusher technique consuming a longer operative time.

Correspondence to: Dr. Mohammed A. Elbanna,

The Department of Gastrointestinal, Liver and Laparoscopic Surgery, Faculty of Medicine, Tanta University
Key Words: Hand-made endoloop knot pusher-Standard endoloop-Base ligation cost-Laparoscopic appendectomy.

\section{Introduction}

LAPAROSCOPIC appendectomy (LA) is currently a well-established and widely accepted method. It has a lot of advantages as compared with open approach technique, including less pain in the postoperative period, faster return to normal activity and work, shorter hospital stay and lower percentage of wound infections [1,2]

Adequate closure of the appendix stump is very important to avoid serious complications such as postoperative fistula, peritonitis, and sepsis. During LA, several modifications with new materials have been introduced for optimizing and controlling the appendiceal stump closure including; staplers, endoloop, titanium clips, non absorbable polymer clips (Hem-o-lock clips), hand-made loops and suture closure [3]

The Endoloop is a commercial product that is commonly used in laparoscopic appendectomy. It can be made of vicryl or polyglactin, and can be of various thicknesses [4].

Using Endoloop has been proposed by several authors due to its safety in closing the appendix stump and its lower cost as compared to staplers [5].

Handmade loops are prepared during surgery and are applied analogous to Endoloop. The cost of this method, which is easy to construct and apply, is significantly lower and can be safely applied [6] 


\section{Patients and Methods}

This study is a prospective randomized comparative study included 40 patients, admitted to Gastrointestinal, Liver \& Laparoscopic Surgery unit of Tanta University Hospitals, Elgharbeia, Egypt that were diagnosed as appendicitis and were subjected to laparoscopic appendectomy starting from May 2017 till May 2018. The forty patients were divided into 2 equal groups; Group I were subjected to ligation of the base of the appendix with standard endoloop (commercial) in laparoscopic appendectomy (20 cases). Group II were subjected to ligation of the base of the appendix with hand-made endoloop knot pusher in laparoscopic appendectomy (20 cases).

All cases that diagnosed as clinically evident appendicitis preoperatively were included in our study except; patient under 18 years of age, perforated appendicitis with peritonitis, preoperatively diagnosed appendicular mass or abscess, severely septic patients for whom a laparotomy is indicated, patients with severe lung or cardiac diseases, and pregnancy.

All patients were subjected to; history taking with emphasis on; onset, course and duration of pain, clinical examination with emphasis on; pulse, temperature, maximum point of tenderness and cough tenderness, right iliac fossa rebound tenderness, guard, rigidity or palpation of a mass, Rovsing's sign, psoas sign and obturator internus sign. Also investigations were done in form of; total leucocytic count, C-reactive protein, urine analysis, pregnancy test in females and imaging studies in form of; Pelviabdominal ultrasound and plain Xray of the abdomen and pelvis in erect position.

\section{Surgical technique:}

Creation of pneumoperitoneum was done by either closed or open techniques through supraumbilical incision. We used carbon dioxide for insufflation with a range pressure of $12-14 \mathrm{mmHg}$, when pneumoperitoneum is established, the $30^{\circ} 10 \mathrm{~mm}$ telescope is inserted inside the umbilical port.

We utilized a three-port technique, with one umbilical $10 \mathrm{~mm}$ port for the camera and the first $5 \mathrm{~mm}$ working port at midline $4-5 \mathrm{~cm}$ above the pubis under laparoscopic vision with care to avoid injury of the bladder, the second $5 \mathrm{~mm}$ working port at left iliac fossa medial to left anterior superior iliac spine.

Firstly identification of the appendix in the right iliac fossa was done and confirmation of the diagnosis, then mobilization and holding the appendix with atraumatic grasper with traction towards anterior abdominal wall, any adhesions between the appendix and the surrounding structures were lysed with a combination of blunt and sharp dissection.

The mesoappendix is then cauterized using unipolar diathermy starting from the tip of the appendix to its base combining the coagulation and cutting electrocautery.

\section{Ligation of the base of appendix:}

In Group I: We use a standard endoloop (commercial endoloop) as (Ethicon Endosurgery, Johnson, Ohio). Introduced into the abdominal cavity through left iliac fossa $5 \mathrm{~mm}$ port and applied on the base of the appendix by holding its tip then pulling the free end of the endoloop and tighten the knot on the base, Ligation of the appendicular base was carried out using 2 standard endoloops placing of them in the proximal portion of the appendicular base and one knot a few millimeters distally.

In Group II: We use a handmade loop with (no. (0) Vicryl) and a Knot pusher made from Stainless-steel that characterized by; autoclavable so used in several cases, hard enough for more tightened loop knot, it's about $40 \mathrm{~cm}$ in length that useful in manipulation at the field and in obese patient as a deep field, lastly its tip length is about $4 \mathrm{~cm}$ and Tip opening diameter about $2 \mathrm{~mm}$ so we can use a different type and different diameter of filament.

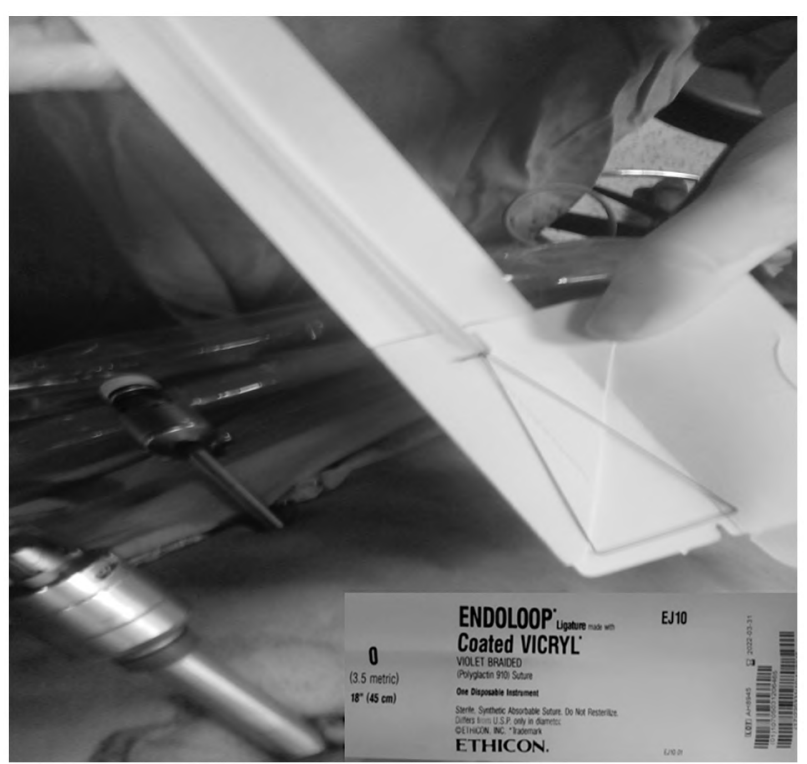

Fig. (1): Standard endoloop (Ethicon.T.M.). 
Fig. (2): The proximal knot ligation of appendicular base with standard endoloop. (Group I).

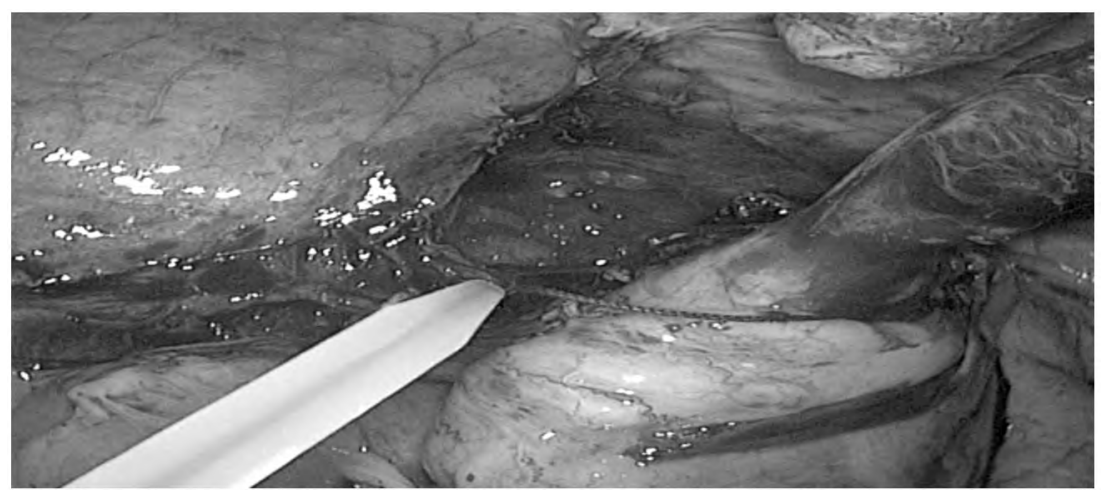

To form the loop: We use the formula (1:3:1); firstly, a loop was made around a post and then a simple knot was made, then With the shorter end, three winds were made around both posts, after that we secured the three wind with the last half hitch, lastly; we tightened the loop and checked for sliding.

After adjustment of the loop on the knot pusher, we insert this handmade endoloop knot pusher in the peritoneal cavity through the left iliac fossa $5 \mathrm{~mm}$ port, then by pulling one end of the loop, the knot has slided down the base of the appendix, We can refire the handmade knot pusher then reinserted into the abdominal cavity. The loop is moved over to the base of appendix, which was ligated by 3 manually made loops, placing two of them in the proximal portion of the appendicular base, and one a few millimeters distally.

Lastly in both groups appendectomy was performed by cutting the appendix distal to the 2 proximal knots, using endoscopic scissors and grasping the appendix from the cutten end then retrieved through the umbilical trocar by pushing it step by step with a grasper in front of camera to the outside (Rendezvous technique).

Fig. (3): Adjustment of the hand made loop (vicryl no 0) on the handmade knot pusher.

Fig. (4): Proximal two tight knots of appendicular base with hand-made endoloop knot pusher.
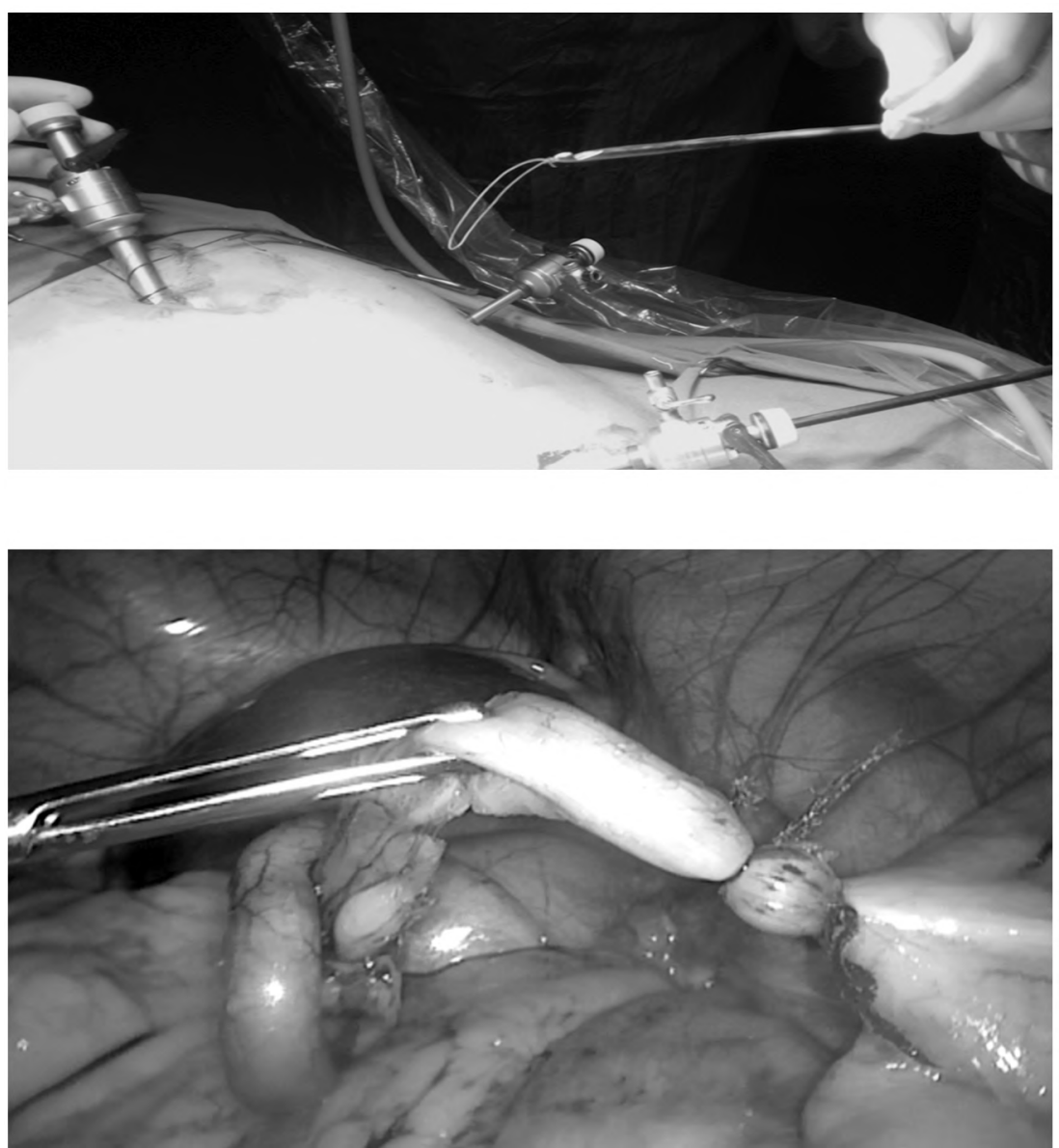


\section{Results}

Total number of patients in our study was 40 patients that were divided into two equal groups:

Group I (GI): Was subjected to ligation of the base of the appendix with standard endoloop (20 cases).

Group II (GII): Was subjected to ligation of the base of the appendix with hand-made endoloop knot pusher (20 cases).

The demographic characteristics of our study groups:

The age characteristics of both study groups showed that the mean age of group I was $29 \pm 5.10$ years, compared to $29.33 \pm 5.39$ in-group II without any statistically significant difference between both groups. There were 12 males $(60 \%)$ and 8 females $(40 \%)$ in group I, while there were 10 males $(50.0 \%)$ and 10 females $(50.0 \%)$ in group II. No statistically significant difference was found in gender between both study groups.

\section{Alvarado score:}

In group I; the mean of Alvarado score was $6.87 \pm 1.68$ while in group II the mean of Alvarado score was $7.33 \pm 1.63$. No statistically significant difference was found as regards Alvarado score between both study groups.

Table (1): Alvarado score characteristics of the study groups.

\begin{tabular}{llcccc}
\hline & G & Range & Mean \pm S.D & $t$-test & $p$-value \\
\hline Alvarado & G I & $5-9$ & $6.87 \pm 1.68$ & -0.879 & 0.385 \\
score & G II & $5-9$ & $7.33 \pm 1.63$ & & \\
\hline
\end{tabular}

\section{Operative data:}

Creation of pneumoperitoneum was accomplished through open technique in one patient in each group while in the other 38 patients we used closed method technique.

Regarding drain insertion; in group I; we inserted a tube drain in 6 patients $(30.0 \%)$. While in-group II we inserted a drain in 4 patients $(20.0 \%)$, with statistically insignificant difference between both groups.

Regarding operative time there was statistically significant difference in between both groups. Group I had a relative shorter operative time than group II. Group I had operative time mean of $46.07 \pm 11.70$ minutes compared to $54.73 \pm 11.33$ minutes in-group II.
Table (2): The mean operative time among our study groups.

\begin{tabular}{llllll}
\hline & $\mathrm{G}$ & Range & Mean \pm S.D & $t$-test & $p$-value \\
\hline $\begin{array}{l}\text { Operative } \\
\text { time }\end{array}$ & G I & $30-66$ & $46.07 \pm 11.70$ & -2.378 & $0.023^{*}$ \\
\hline
\end{tabular}

\section{Type of the appendix:}

In-group I; simple appendicitis was found in 12 patients $(60 \%)$, complicated appendicitis in 5 patients $(25 \%)$, and no macroscopic signs of inflammation in 3 patients $(15 \%)$. On the other hand, in group II simple appendicitis was found in 10 patients $(50 \%)$, complicated appendicitis in 7 patients $(35 \%)$, and no macroscopic signs of inflammation in 3 patients $(15 \%)$.

Post-operative return of intestinal sounds \& starting feeding:

We started oral feeding in group I after $19.33 \pm$ 6.21 hours postoperatively, while in group II it returned after $20.88 \pm 7.11$ hours, with $p$-value $=0.101$ which is statistically insignificant.

\section{Post-operative complications:}

Superficial wound infection developed in one patient $(5.0 \%)$ in group I and two patients $(10.0 \%)$ in group II, also each group had only one patient $(5.0 \%)$ with postoperative ileus which resolved within 48 hour under conservative treatment (nasogastric tube, nothing per month, intravenous fluids and bowel stimulants), but regarding intraabdominal abscess there was only one patient in group II $(5.0 \%)$ who has postoperative abscess in the RIF and was treated by the placement of ultrasound-guided percutaneous tube drain into the abscess under the cover of parental antibiotic regimen.

Additionally, there was no patient developed fecal fistula or bleeding. No significant statistical difference between two groups in postoperative complications.

Duration of hospital stay in days among the study groups:

9 cases $(45.0 \%)$ in group I were discharged in 1 st postoperative day in comparison to 8 cases $(40.0 \%)$ in group II. 10 cases $(50.0 \%)$ were discharged in 2nd postoperative day in group I, while 11 cases $(55.07 \%)$ were discharged in 2 nd postoperative day in group II, one case $(5.0 \%)$ in each group was discharged in $3 \mathrm{rd}$ postoperative day who was represented with ileus, another case (5.0\%) in group II was discharged in 4 th postoperative day and one week later during his first follow-up visit at outpatient clinic represented with intra-abdominal 
abscess which was treated by the placement of ultrasound-guided percutaneous tube drain into the abscess under the cover of parental antibiotic regimen.

Patient was discharged when he was vitally stable, full oral feeding, no signs of early postoperative complications. All of the 30 patients in this study were followed-up weekly in the first month.

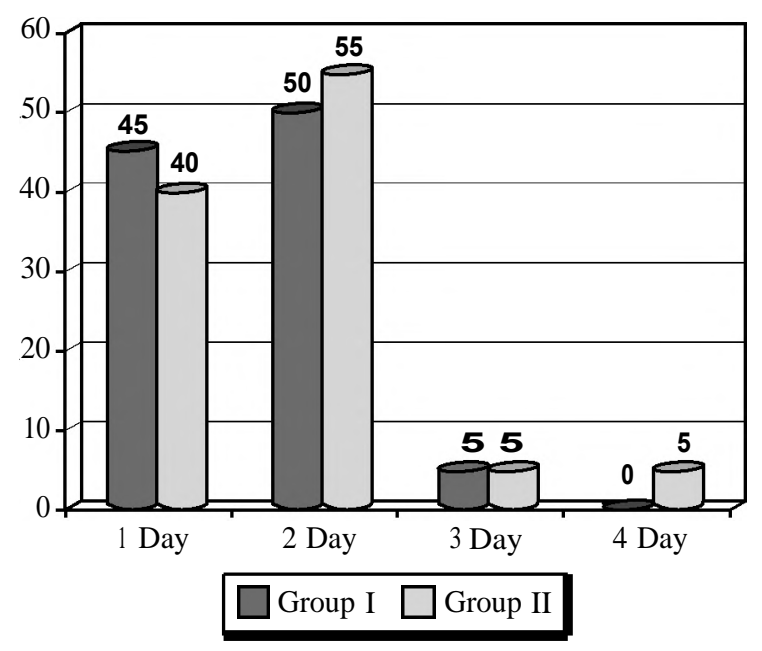

Fig. (5): The hospital stay among both groups.

\section{Cost of appendiceal base ligation:}

We used 2 or 3 disposable standard endoloop (Ethicon) for ligation of the base of appendix in group I at a cost of 54-81 USD = (27 USD) $\mathrm{x}(2-$ 3 ). In a reusable hand-made knot pusher we use one or two packages vicryl (0) in group II, at a cost of 5-10 USD.

In both groups vicryl -0- suture for fascial closure of umbilicus and one prolene 4.0 suture for skin closure, all the instruments we used were reusable except 2 disposables standard endoloops.

A highly significant statistical difference between both groups in appendiceal base ligation Cost as group I with Mean \pm S.D 69.10 \pm 10.41 , group II with Mean \pm S.D $7.75 \pm 1.77$ and $p$-value $<0.001 *$.

Table (3): Cost of appendiceal base ligation during operation among the study groups.

\begin{tabular}{cccccc}
\hline & Cost Range & Mean \pm S.D & $\begin{array}{c}t- \\
\text { test }\end{array}$ & $\begin{array}{c}p- \\
\text { value }\end{array}$ \\
\hline $\begin{array}{l}\text { Appen diceal } \\
\text { base ligation } \\
\text { cost: }\end{array}$ G I & $54-81$ & $950-1.450-81$ & $69.10 \pm 10.41$ & 25.9 & $<0.001^{*}$ \\
& USD & L.E. & & & \\
G II & 5-10 & $90-180$ & $7.75 \pm 1.77$ & & \\
& USD & L.E. & & & \\
\hline
\end{tabular}

\section{Discussion}

Appendicular stump closure is a crucial step during laparoscopic appendectomy, and its inappropriate management can lead to catastrophic complications. Different techniques have been described to secure the appendicular base [3] , and despite many studies, there is no universal agreement on any method, staplers can be considered when the appendix base is extremely inflamed or necrotic but unfortunately, staplers and endoloops are more expensive methods as compared to others. Using cheaper alternatives such as ligation with sutures and handmade loops will be more appropriate, due to the particular conditions of poor countries. All methods have a similar reliability, therefore methods that are cheap and easy to apply should be considered as first choice. Nevertheless, the final decision on the method to be used will rely on the surgeon's training and experience, the availability of equipments, costs and the extent of appendix inflammation [1].

Endoloops (Sliding knots) are easy to create, and the surgeon who advances the knot controls the tension. The majority of extracorporeal knots are sliding knots, and this raises concerns about the safety of the ligatures. Due to numerous difficulties and challenges to intracorporeal knot tying, the surgeons try to avoid intracorporeal suturing and make use of extracorporeal technique [7].

Commercial endoloops use the knot which Hans Albert Roeder patented in 1931 for use during tonsillectomy, several modifications have been described [7]. Other low-cost endoloops have been described, but these do not use a pusher as do the commercial endoloops [8]

Alternative methods described for endo-loop placement need a grasper to hold the smaller end and a pusher to place the knot in the correct place [7].

In this study we tried to compare securing the base of the appendix using standard endoloop in group (I) versus handmade endoloop knot pusher in group (II) as regard: (Simplicity, operative time, effectiveness, complications and cost).

The presenting age of patients participating in Group (I) was $29.00 \pm 5.10$ years ranged from 20 35 years while in the Group (II) mean age was $29.33 \pm 5.39$ years ranged from $23-39$ years, with no statistically significant difference between both groups.

Our result is similar to Chand Prem et al., 2017, who reported in their study comparing Intracorpor- 
eal knot with endoloop that the mean age of all patients was 29.01 years, and they explained the cause of high incidence of appendicitis in the second and third decade of life is considerably due to hyperplasia of lymphoid tissue in the appendix, which reaches its peak at 20 years of age and thereafter atrophy of the lymphoid tissue begins [9].

Nadeem et al., 2016 reported in their study comparing Endoloop (sliding knot) that (36 patients) with metallic endoclip (32 patients), that the mean age of Endoloop group was $24 \pm 7.78$ years [10].

In our study; Group (I) showed 12 males (60\%) and 8 females (40\%), while Group (II) were consisted of 10 males $(50.0 \%)$ and 10 females $(50.0 \%)$. No statistically significant difference was present in gender between both study groups.

Arcovedo et al., 2007 reported in their study comparing Gea sliding-knot with stapler that there were 34 male patients (54\%) and 29 female patients $(46 \%)$ in Extracorporeal group [11]

The operative time; in our study there was statistically significant difference between both groups with $p$-value $=0.023$. Group (I) had a shorter operative time than group (II). Group (I) had operative time mean of $46.07 \pm 11.70$ minutes compared to $54.73 \pm 11.33$ minutes in group (II).

The operative time in our study is similar to Nguyen et al., that evaluated two different types of knot-tying techniques-intracorporeal versus extracorporeal they found in their study a statistically significant difference between the two methods with a performance time for the extracorporeal knot tying technique less than that for the intracorporeal technique with $p$-value $>0.05$ [12]

Gonenc et al., 2012, reported in their study comparing hand-made endoloop sliding knot versus metal endoclip that the mean operative time of hand-made endoloop group (46 patients) was 61.9 minutes [13], also M. Kieudelis et al. found in their study comparing invaginating endosuture versus endoloops that the mean operative time of endosuture group (40 patients) was $79.6 \pm 21$ minutes. Time was significantly longer because invaginating suture was also used in the study [14].

M. Nadeem et al., 2016, reported in their study comparing Endoloop Sliding knot (36 patients) with that nonsignificant difference in time as the mean operative time of sliding knot group was
$48.3 \pm 8.45$ minutes and the mean operative time of metallic endoclip was $44.3 \pm 8.45$ minutes [10]

Drain insertion; in group (I); we inserted a tube drain in 6 patients $(30.0 \%)$. While in group (II) we inserted a tube drain in 4 patients $(20.0 \%)$, with $p$-value $=0.715$, which statistically insignificant. All drains were removed in the second day postoperative.

Among the 40 studied patients no patients needed laparotomy and no cases of mortality or intraoperative complications were reported in this study.

M. Kieudelis et al., 2013 reported in their study comparing invaginating suture versus endoloops that one patient of endosuturing group (40 patients) has intraoperative bleeding [14].

M. Nadeem et al., 2016 reported in their study comparing Endoloop (36 patients) with metallic endoclip that one patient has intraoperative bleeding in Endoloop group [10]

In our study the oral feeding returned in Group (I) after $17.33 \pm 6.21$ hours postoperatively and in Group (II) after $20.88 \pm 7.11$ hours, with $p$-value $=$ 0.101 which is statistically insignificant.

One patient in each group developed postoperative ileus which resolved within 48 hour under conservative treatment (nasogastric tube, nothing per month, intravenous fluids and bowel stimulants).

Chand, Prem, et al., 2017, reported in their study on 60 patients that the bowel sounds in patients of sliding knot group (30 patients) returned after $18.80 \pm 8.14$ hours [9].

Regarding postoperative complications: Only one patient $(5.0 \%)$ in group (I) developed superficial wound infection, while two patients $(10.0 \%)$ in group (II) had wound infection and regarding intra-abdominal abscess there was one patient only in group (II) that has postoperative abscess in the right iliac fossa (5.0\%), only one patient in group (I) $(5.0 \%)$ developed port site hernia at 3 rd month and one patient in group (II) (5.0\%) developed adhesions (adhesive intestinal obstruction) at 6 th month.

Additionally no patient developed bleeding, collection, fecal fistula and chronic abdominal pain during the time of postoperative follow-up, No significant statistical difference between two groups as regards postoperative complications. 
The three patients who developed superficial wound infection were managed with regular wound care and antibiotics. One patient who developed intra-abdominal abscess was treated by the placement of ultrasound-guided percutaneous tube drain into the abscess under the cover of parental antibiotic regimen.

One patient who developed port site hernia was admitted for repair and one patient who developed adhesions (adhesive intestinal obstruction) was treated conservatively.

According to our study, the decreased incidence of intra-abdominal abscess formation was due to the proper peritoneal irrigation, suctioning, fragments removal, using drains whenever needed, and proper antibiotic administration. Therefore, these complications are probably not result from the technique per se, but may reflect the difficult situation of the complicated appendicitis.

The postoperative complication rates observed in this study were similar to that in other reports $[15,16]$. No significant statistical difference between two groups as regards postoperative complications in these studies. It is noteworthy that only patients with complicated appendicitis had reported postoperative complications.

M. Nadeem et al., 2016, reported in their study comparing sliding knot (36 patients) with metallic endoclip that one patient in group has postoperative delayed peristalsis [10]

In our study, 9 cases (45.0\%) in group I were discharged in 1 st postoperative day in comparison to 8 cases $(40.0 \%)$ in group II, while in the 2 nd postoperative day, 10 cases $(50.0 \%)$ in group I were discharged in comparison to 10 cases $(50.0 \%)$ in group II, in the 3 rd day one case $(5.0 \%)$ discharged in each group, in postoperative 4 th day one patient $(5.0 \%)$ in group II discharged with no statistically significant difference between the two groups.

Elshoura, Ahmed et al., 2017, found in their study that in endostapler group the average hospital stay was 1.73 days (range: 1-7 days); in sliding Knot group it was 1.8 days (range: $1-12$ days); and in it was 2.3 days (range: 1-5 days). In their study, the procedure used for endosuturing group was technically difficult: It had the longest hospitalization stay, as patients needed a longer observation period [17].

The average length of hospitalization in recent studies (Strzalka, et al. 2016, Gomes et al., 2013) was from 2 to 5.9 days, showing no statistically significant difference among the various approaches of appendix stump closure $[\mathbf{1 5 , 1 6}]$

Regarding the cost, Laparoscopic appendectomy cost changes according to surgical material used; in our study we used one or two packages of Vicryl ligatures no: (0) for ligation of the base of appendix with two or three loops using a reusable handmade endoloop knot pusher in group (II) with mean $7.75 \pm 1.77$, and two or three disposable commercial standard endoloop (Ethicon.T.M) in group (I) with mean $69.10 \pm 10.41$, in both another vicryl -0-suture for fascial closure of umbilicus, and one prolene 4.0 suture for skin closure, all the other instruments we used were reusable, this study $p$-value was $<0.001 *$ which demonstrate the highly significant cost of appendiceal base ligation using standard endoloop in group (I).

Chikamori, et al., realize that ligation of the appendicular base should be only moderately tight. The degree of tension applied to the knot is very important as loose knot may cause bleeding or postoperative leakage and collection, also tight closure of the applied knot resulting in cutting or tearing of the tissues, which necessitates conversion to open surgery with transfixing the appendicular stump [18]

Laparoscopic operative procedures are still more expensive than open surgery, and this is one of the main drawbacks. The cost of laparoscopic appendectomy is based on the disposable equipment, such as endostaplers, endoloops, and trocars. $[19,20]$

Rickert et al., used a titanium double-shanked clip (DS-Clip) in their study. They concluded that the titanium DS-Clip is a safe and cost-effective technique for securing the appendix base in laparoscopic appendectomy. The application is easy, and can be learned quickly, making it a good option for teaching hospitals. With this type of clip, appendix stumps with a diameter of up to $20 \mathrm{~mm}$ could be safely closed. The disadvantage of this method is the need for a $12.5-\mathrm{mm}$ trocar for introducing the cli $\mathrm{p}$ applicator. The price for a set of four clips is predicted to be around 80ณ, depending on the region [21]

In this study, we used 2 or 3 standard endoloops for closing the base of the appendix in group (I) at a cost of 54-81 USD. In group (II), one or two packages of Vicryl ligatures no (0) which was enough for closing the base of the appendix with 2 or 3 hand-made loops at a cost of 5-10 USD. There was a highly significant difference between 
both groups regarding the cost of appendiceal base ligation.

In some studies, it is concluded that one endoloop was as safe as using 2 or more if the appendix is inflamed minimally [21].

Nevertheless, in most studies, 2 endoloops were placed at the base of the appendix, and another endoloop, clips, or ligature is used to ligate the appendix distal to the endoloops before dividing the appendix [22]

Beldi, et al., also preferred placing 2 ligatures in the proximal portion of the appendicular base, and one a few millimeters distally. The operating room time was similar between both groups, due to the similarity of the techniques. Moreover, the time spent for tying the loop was approximately 30 seconds. In addition, there were no significant differences in length of hospital stay and complication rates in both groups, also they reported in their statistical studies that significant cost advantage makes the handmade endoloop the preferred operative method. In conclusion, laparoscopic appendectomy by closing the base of appendix using the handmade endoloop technique may be a more cost-effective technique [23]

Our study showed that hand-made endoloop knot pusher usage is effective in appendiceal stump closure and its safety is similar to that of Standard endoloop knot pusher usage with no significant difference in perioperative or postoperative outcome between the two groups. There is also no significant difference on the length of hospital stay, as a hand- made endoloop knot pusher consuming longer time there was a significant difference in operative time and a highly significant difference between the two groups regarding the cost as a hand-made endoloop knot pusher was much cheaper than the standard endoloop.

\section{Conclusions:}

In this study, both techniques using hand-made endoloop knot pusher technique and using standard endoloop were proved safe, as there were not associated with major morbidity. Complications rate, hospital stay were average with other studies, Using hand-made endoloop knot pusher technique has significant lower cost in comparison with using standard endoloop as it is reusable. However, handmade endoloop knot pusher technique consuming a longer operative time.

Although, commercial endoloop (standard) is much easier to use, further studies in a wider range may be needed to gain consensus about the best method for appendiceal base ligation regarding safety and cost effectiveness.

We recommend that every laparoscopic surgeon must be acquainted by using extracorporeal handmade sliding knot with hand-made knot pusher in laparoscopic appendectomy.

\section{References}

1- MAYIR B., ENSARI C.O., BILECIK T., ASLANER A. and ORUC MT.: Methods for closure of appendix stump during laparoscopic appendectomy procedure. Ulus Cerrahi Derg., 31(4): 229-31, 2015.

2- GULLER U., HERVEY S., PURVES H., MUHLBAIER L.H., PETERSON E.D., EUBANKS S., et al.: Laparoscopic versus open appendectomy: Outcomes comparison based on a large administrative database. Ann. Surg., 239 (1): 43-52, 2004.

3- SHAIKH F.M., BAJWA R. and McDONNELL C.O.: Management of appendiceal stump in laparoscopic appendectomy-clips or ligature: A systematic review and metaanalysis. J. Laparoendosc. Adv. Surg. Tech. A., 25 (1): 21-7, 2015.

4- MIYANO G., URAO M., LANE G.J., KATO Y., OKAZAKI T. and YAMATAKA A.: A prospective. Analysis of endoloops and endostaples for closing the stump of the appendix in children. J. Laparoendosc Adv. Surg. Tech. A., 21: 177-179, 2011.

5- SAHM M., KUBE R., SCHMIDT S., RITTER C., PROSS M. and LIPPERT H.: Current analysis of endoloops in appendiceal stump closure. Surg. Endosc., 124-129: 25 , 2011.

6- YILDIZ F., TERZI A., COBAN S., ZEYBEK N. and UZUNKOY A.: The handmade endoloop technique. A simple and cheap technique for laparoscopic appendectomy. Saudi Medical Journal, 30 (2): 224-227, 2009.

7- MURAD F., ALI Q., MASIHA S.A., SHAH A., ILYAS A., YOUNAS S., ANWAAR A. and ZAFAR A.: Roeder's knot: Solution to intra-corporeal knot tying. J. Rawalpindi Med. Coll. (JRMC), 17: 181-4, 2013.

8- RAKIC'M., JUKIC' M., POGORELIC'Z., MRKLIC' I., KLICEK R., DRUZIJANIC' N., et al.: Analysis of endoloops and endostaples for closing the appendiceal stump during laparoscopic appendectomy. Surgery Today, 44 (9): 1716-22.

9- CHAND P., SINGH G., KAHLON P.S., SINGH D. and GUP-TA A.: Comparison of Stump Closure Techniques of the Base of the Appendix in Laparoscopic Appendectomy. Journal of Evolution of Medical and Dental SciencesJEMDS, 6 (72): 5092-7, 2017.

10- NADEEM M., KHAN S., ALI S., SHAFIQ M., ELAHI M., ABDULLAH F., et al.: Comparison of extra-corporeal knot-tying suture and metallic endo-clips in laparoscopic appendiceal stump closure in uncomplicated acute appendicitis. International Journal of Surgery Open, 2: 11-4, 2016.

11-ARCOVEDO R., BARRERA H. and REYES H.S.: Securing the appendiceal stump with the Gea extracorporeal sliding knot during laparoscopic appendectomy is safe and economical. Surg. Endosc., 21 (10): 1764-7, 2007. 
12- NGUYEN N.T., MAYER K.L., BOLD R.J., LARSON M., FOSTER S., HO H.S., et al.: Laparoscopic suturing evaluation among surgical residents. The Journal of Surgical Research, 93 (1): 133-6, 2000.

13- GONENC M., GEMICI E., KALAYCI M.U., KARABULUT M., TURHAN A.N. and ALIS H.: Intrac-orporeal knotting versus metal endoclip application for the closure of the appendiceal stump during laparoscopic appendectomy in uncomplicated appendicitis. J. Laparoendosc Adv. Surg. Tech A., 22, 2012.

14- KIUDELIS M., IGNATAVICIUS P., ZVINIENE K., et al.: Analysis of intracorporeal knotting with invaginating suture versus endoloops in appendiceal stump closure. Wideochir. Inne. Tech. Maloinwazyjne, 8 (1): 69-73, 2013.

15- STRZALKA M., MATYJA M. and REMBIASZ K.: Comparison of the results of laparoscopic appendectomies with application of different techniques for closure of the appendicular stump. World J. Emerg. Surg., 11: 4, 2016.

16- GOMES C.A., JUNIOR C.S., DE PEIXOTO R.O. NETTO J.M.B., GOMES C.C. and GOMES F.C.: Appendiceal stump closure by metal endoclip in the management of complicated acute appendicitis. World Journal of Emergency Surgery, 8 (1): 35, 2013.

17-ELSHOURA A., HASSAN O. and SABER S.: Application of different methods for stump closure in laparoscopic appendectomy. The Egyptian Journal of Surgery, 36 (2): 131, 2017.

18- CHIKAMORI F., KUNIYOSHI N., SHIBUYA S. and TAKASE Y.: Appendiceal stump abscess as an early complication of laparoscopic appendectomy: report of a case. Surgery Today, 32 (10): 919-21, 2002.

19- ORTEGA A.E., HUNTER J.G., PETERS J.H., SWANSTROM L.L. and SCHIRMER B.: A prospective, randomized comparison of laparoscopic appendectomy with open appendectomy. Laparoscopic Appendectomy Study Group. Am. J. Surg., 169: 208-212, 1995.

20- COTHREN C.C., MOORE E.E., JOHNSON J.L., MOORE J.B., CIESLA D.J. and BURCH J.M.: Can we afford to do laparoscopic appendectomy in an academic hospital? Am. J. Surg., 190: 950-954, 2005.

21- RICKERT A., BONNINGHOFF R., POST S., WALZ M. RUNKEL N. and KIENLE P.: Appendix stump closure with titanium clips in laparoscopic appendectomy. Langenbecks. Arch. Surg., 397: 327-31, 2012.

22- HANSSEN A., PLOTNIKOV S. and DUBOIS R.: Laparoscopic appendectomy using a polymeric clip to close the appendicular stump. JSLS, 59-62: 11, 2007.

23- BELDI G., MUGGLI K., HELBLING C. and SCHLUMPF R.: Laparoscopic appendectomy using endoloops: A prospective, randomized clinical trial. Surg. Endosc., 18: 749-750, 2004. 


\section{دراسة مقارنة بين ريط قاعدة الزائدة الدودية

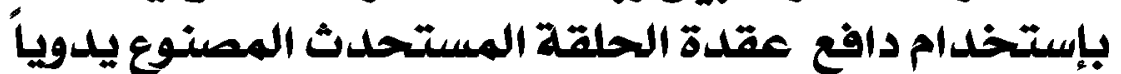

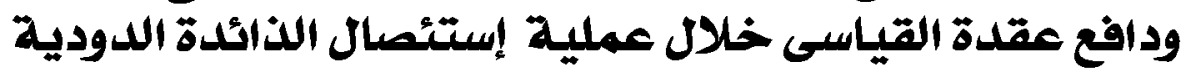

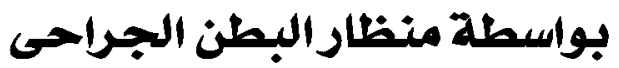

يعتبر إلتهاب الذائدة الدودية من أهم الأسباب وأبرذها لألم البطن الحاد، ويتطلب العلاج الجراحى المستعجل تفاياً لمضاعفات الحالة.

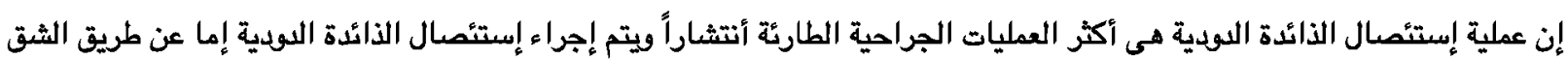

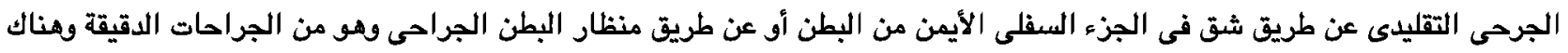

طرق عديدة لإستئصال الذائدة الدودية بهذه الجني الطريقة.

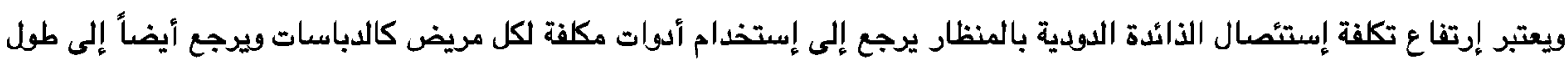

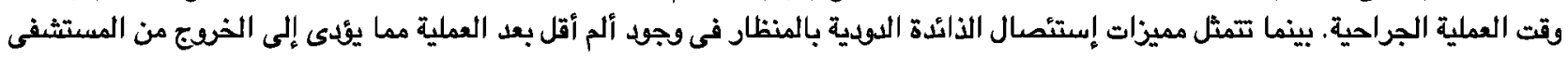

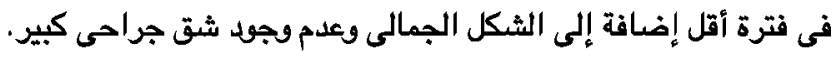

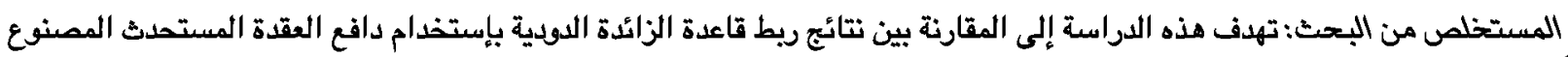

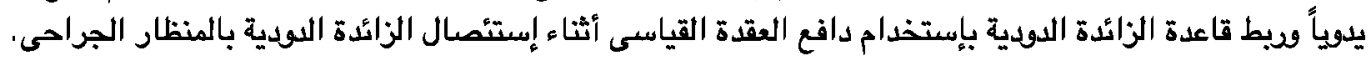

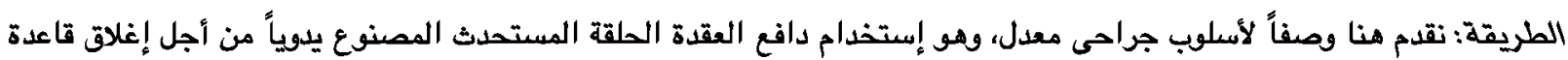

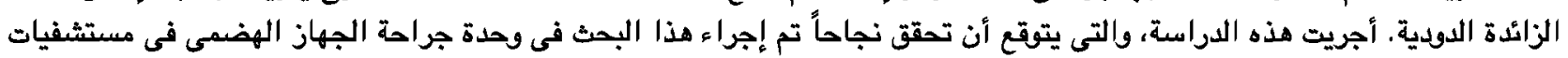

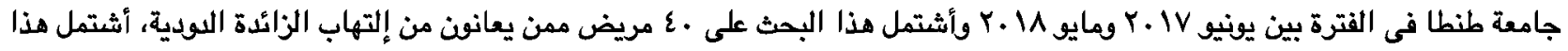

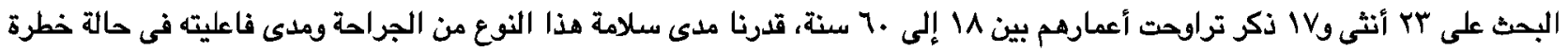

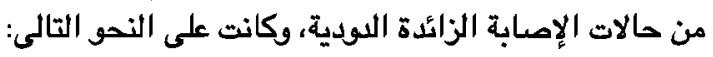

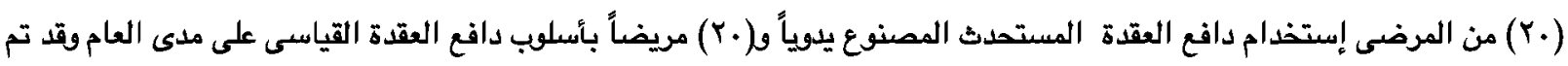

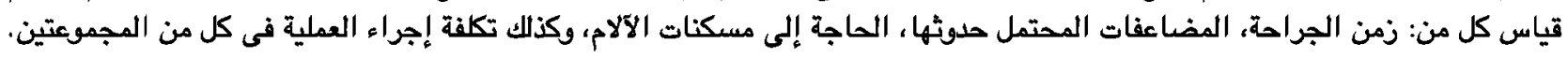

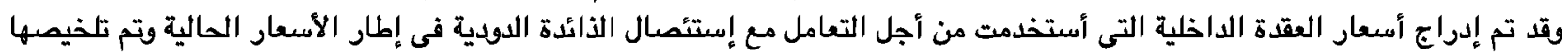

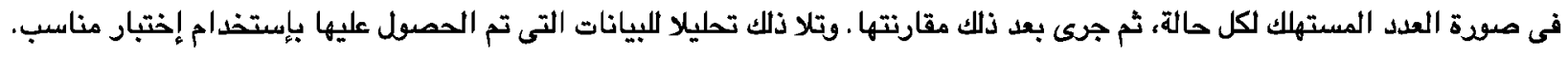

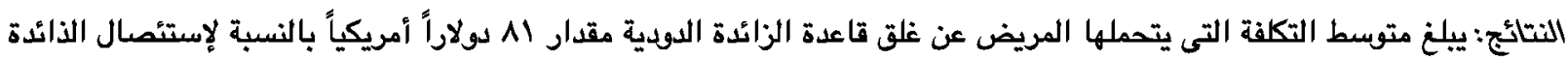

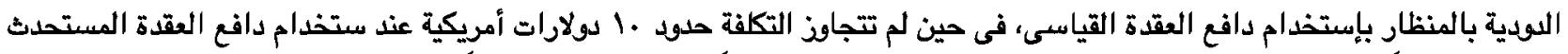

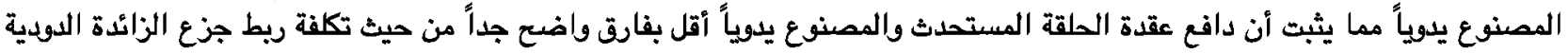

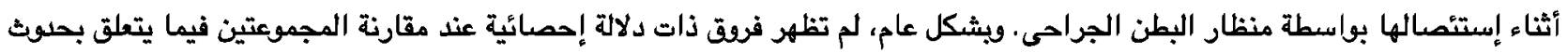

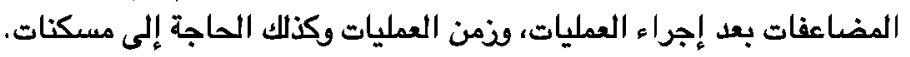

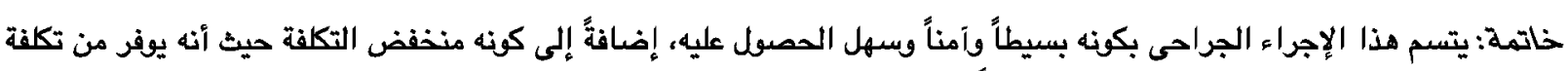
جراحة إستئمال الذائدة الدودية بالمنظار ويعطى رواجاً لجراحة المناظير على مستوى الدول الفقيرة. 